\title{
Virtual Leadership Matters: Capturing its Role in Facilitating Knowledge Sharing in Virtual Learning Environment
}

\author{
Xiaolong Wei \\ Chonnam National University \\ fenglangzi0925@126.com
}

\author{
Ilsang Ko \\ Chonnam National University \\ isko@chonnam.ac.kr
}

\begin{abstract}
Many educational institutions and organizations have attempted to encourage knowledge sharing by implementing virtual learning communities. During the COVID-19 pandemic, how to utilize virtual communication technologies to effectively facilitate knowledge sharing among geographically dispersed learners has become an extremely urgent issue. Our study investigated 88 undergraduates (nested in 10 groups) from a University in Southwest China. The research results reveal that self-presence and virtual member trust are the primary determinants in facilitating knowledge sharing (explicit vs tacit) in a virtual learning environment (VLE). Additionally, considering the challenges of forming effective collaborations in VLE (e.g., environment uncertainty, and one-way oriented communication), virtual leadership for improving the coordination of joint activities was developed. Virtual leadership improves the climate of a virtual learning environment by strengthening the relationships between selfpresence/virtual member trust and knowledge sharing. Finally, the positive inter-relationship of explicit/tacit knowledge sharing and team performance is confirmed in our research.
\end{abstract}

\section{Introduction}

The development of virtual communication technology (VCT) has offered unprecedented opportunities to collaborate with geographically dispersed colleagues. When confronted with an emergency situation (such as the Coronavirus emergency), VCT can be advantageous in bridging time and space in a cost-effective manner and providing a life-like collaborative environment to make better use of distributed human resources. A great number of studies have examined the organizational use of VCT $[16,26$, 35], such as utilizing virtual communication technologies in VLE [2], which can be particularly effective at the team level [16]. Research [2] has revealed that the biggest challenge in teamwork among students is facilitating effective collaboration, especially in a virtual team context. VCTs are claimed to be essential in communication and knowledge sharing processes among geographically dispersed members $[26,35]$. However, compared to face-to-face offline communication, two notable challenges that inhibit efficient communication and knowledge sharing in VLE have been raised [35, 47]. One is that information transformation is oriented to a one-way process from the sender to the receiver, and this phenomenon will have a greater impact in virtual environments if no effective managing approach exists. Another concern is that separations in time and space lead to "inherent uncertainty" in a virtual environment, which aggravates conflicts among virtual members.

The ability to communicate effectively in a virtual community depends on the active participation of both the receiver and the sender [47]. The human component in the virtual environment, the relational bonds, are the focal elements in determining knowledge sharing or organizational learning $[28,41]$. The ability to shape information in an appropriate and understandable form for receivers determines the conflicts occurring and the communication efficiency [47]. Thus, our research aims to investigate the determinate factors that facilitate efficient knowledge sharing in VLE by deriving selfpresence, virtual member trust, virtual interaction, and virtual leadership.

Self-presence refers to "a state in which users experience their virtual self as if it were their actual self, perhaps even leading to an awareness of themselves inside the virtual environment" [38]. In a study investigating the influence of self-presence in the social virtual world (VW), Behm Morawitz (2012) contended that self-presence rendering the influence of spatial and social presence was positively associated with offline health and appearance. Previous research has indicated that user trust can effectively mitigate inherent uncertainties within the $\mathrm{VW}$ environment, in turn facilitating effective workplace collaboration [35]. "Trustworthy relationships enable individuals to engage 
more openly in activities and knowledge exchanges in the collective" [6]. We assume that in VLE, virtual member trust associates effective co-creating collaboration by mitigating conflicts induced by the "inherent uncertainties" of virtual worlds and engaging participants in active knowledge sharing. In conventional web-based VLEs [27, 49], virtual interaction is examined in terms of interaction with content, interaction with instructors, and interaction among learners, and research has consistently indicated that virtual interaction improves collaborative learning. Similarly, confronted with the current pandemic, we conceive that virtual interaction can serve as an effective mechanism by connecting self-presence, virtual member trust in facilitating efficient communication, and knowledge sharing in VLE. In the "real" world, the primary role of leadership is "influencing others to understand and agree about what needs to be done and how to do it, and the process of facilitating individual and collective efforts to accomplish shared objectives" [46]. We conceptualize "virtual leadership" in VLE similarly and assume that it can be substantially associated with interactive relationships, thereby facilitating knowledge sharing or organizational learning.

A VLE is a designed information space that can bridge space and time to allow geographically dispersed virtual members to collaborate effectively. However, it would not be honest to claim that VLE will improve the quality of education. Considering the challenges of the one-way oriented information transformation process and the "inherent uncertainty" that occurs in virtual environments, our research aims to explore an effective approach to facilitate knowledge sharing in VLE by deriving self-presence, virtual member trust, and virtual interaction. Accordingly, the first research question that will be discussed in our research is "(1) Will selfpresence and virtual member trust relate to knowledge sharing via virtual interaction in VLE?" On the one hand, studying leadership in VLE is an echo of Faraj et al.'s research [14], which contended that "Despite the growing importance of online communities in creating knowledge and facilitating collaboration, there has been limited research examining the role of leaders in such settings". On the other hand, the associated weakening of control in VWs leads some virtual members into a "leaderless situation" [8]. There is currently a conspicuous lack of research on how to engage participants with an active interactive relationship and how to solve the latent individual conflicts based on a group level approach in a relative long-term VLE while considering the contingency effect of leadership. Hence, the second research question in our study is "(2) Will virtual leadership emphasized on group level relate to the performance of knowledge sharing in VLE?"

\section{Literature Review and Hypothesis Design}

\subsection{Knowledge Sharing in Virtual Learning Teams}

Topchyan [39] referred to a virtual learning team (VLT) as a team made up of distance distributed members who meet exclusively through a course management system to accomplish common goals. VLTs are currently being used in education as well as in corporate training programs. The potential advantages of VLT are that they can foster knowledge sharing behavior while helping their members develop interpersonal and collaborative skills. Nonaka and Takeuchi [29] presented two types of knowledge sharing: explicit knowledge sharing and tacit knowledge sharing, which can both be applied in any field. Explicit knowledge sharing refers to the sharing of knowledge that can be codified and written in a symbolic form, while tacit knowledge sharing refers to knowledge that still resides in the knowledge owner and that has not yet been expressed or codified. Virtual teams (VTs) can efficiently exchange verbal information, but non-verbal exchange has limitations which contribute to increased misunderstandings, which inhibit effective communication and knowledge sharing among members [19, 33]. Studies of groups using computermediated communication have obtained inconclusive results related to efficient communication and knowledge sharing. It is of crucial importance to investigate how to achieve efficient communication and effective knowledge sharing by elucidating the functioning of a virtual learning team, particularly in the face of this urgent COVID-19 pandemic situation.

\subsection{Virtual Leadership}

Serçe et al. [33] contended that studying collaborative behavior in an online learning environment at the group level is a complex process. Team leaders play a crucial role in effective virtual team management and in creating a knowledge-sharing environment. Such leaders co-ordinate activities/tasks, motivate team members, monitor and/or facilitate collaboration, and address/resolve conflict [47]. In our study, we defined virtual leadership by referring to Yilmaz et al.'s [42] e-leadership study, which describes it as a concept of managing group members and group processes using virtual communication technologies and environments. A large number of prior studies have identified leadership as an important factor influencing VT performance, both directly and through the mediation or the contingency between a team's characteristics and performance $[5,22,43]$. 
Yilmaz et al. [42] examined how vertical eleadership and shared e-leadership influence selfregulated learning skills and group collaboration in online project-based learning. Bass et al. [3] presented two active leadership styles, transactional leadership and transformational leadership. Han et al. [16] adapted the Competing Values Framework (CVF) to study virtual leadership and described it in terms of internal and external organization demands. Quinn's [31] CVF also recognizes the paradoxical needs for both flexibility and control. The eight leadership roles formed by CVF represent a set of options for how someone taking leadership initiative might interact with their team to move it toward a shared goal. Strang [36] refers to the Quinn model as "more mature and tested" (p. 448) than other leadership styles. Therefore, Quinn's CVF was used to formulate virtual leadership in our study.

\subsection{Self-presence and Knowledge Sharing}

Researchers [15] have suggested that non-verbal cues are a critical aspect of efficient communication, particularly in high-context cultures. In VLE, the absence of non-verbal cues may initially pose certain difficulties in efficient communication or knowledge sharing, especially for cultures that rely on body language, gestures, facial expressions, and proximity. Biocca [7] introduced the term "self-presence" to represent users' mental models of themselves inside the VWs as it relates to their perceptions of their bodies, physiological states, emotional states, perceived traits, and identities. A higher self-presence represents rich visual cues such as a nod, smile, posture, voice, and eye meanings, all of which establish certain understanding in communication. Without these cues, it may initially be difficult for people to carry out tasks as complex as making decisions or as basic as communicating. We assume that higher self-presence will effectively facilitate communication or knowledge sharing in VLE.

Hypothesis 1: Self-presence will be positively associated with knowledge sharing in VLE.

Hypothesis 1a: Self-presence will be positively associated with explicit knowledge sharing in VLE.

Hypothesis 1b: Self-presence will be positively associated with tacit knowledge sharing in VLE.

\subsection{Virtual Member Trust and Knowledge Sharing}

"Trust diminishes individual's fears of being publicly criticized in, or even expelled from, a collective, providing a certain level of security, protection, and mutual respect" [6]. The ability to collaborate depends heavily upon trust, as open reciprocity and the sharing of information and knowledge cannot freely occur without trust. The establishment of trust-based intra-team relations can foster dialogue, debate, knowledge-sharing, and groupmediated solutions. Studies of VTs have shown that trust among virtual members plays an important role in knowledge sharing [47], team collaboration [19], and team performance [43].

However, research $[2,7,16,41]$ related to VTs has also contended that the lack of physical co-location and non-verbal cues makes it challenging for virtual members to develop trust in their relationships. Joshi et al. [20] found that due to the difficulty of forming close interpersonal bonds, the development of trust is more challenging when team members are dispersed. Johnson et al. [19] summarized that team conflicts among students do not arise from task difficulty, but instead stem from the lack of a willingness to participate, plan, or resolve individual disagreements. Scholars [44] have shown that sense of presence is an important predictor of various responses (i.e., satisfaction, motivation, positive attitude, and positive performance) in VLE. Additionally, Chuang et al. [10] suggested that mutual trust is built from free presence in others, and they argued that people who have a higher sense of telepresence are more likely to trust each other, and in turn more likely to have active communication.

Based on the above discussion, we make the following hypotheses in this research.

Hypothesis 2: Virtual member trust will be positively associated with knowledge sharing in VLE.

Hypothesis 2a: Virtual member trust will be positively associated with explicit knowledge sharing in VLE.

Hypothesis 2b: Virtual member trust will be positively associated with tacit knowledge sharing in VLE.

Hypothesis 3: Self-presence will be positively associated with virtual member trust in VLE.

\subsection{The Moderating Effects of Virtual Leadership}

Compared to general VWs, more members will participate in VLEs. The greater the degree of virtualization, the more people need to manage their relationships, share knowledge and expertise, and coordinate joint activities in completely new ways. Additionally, Johnson et al. [19] contended that in VLE, the lack of a willingness to participate in teamwork is the most challenging issue that leads to the occurrence of conflicts. Special considerations for effective leadership are required in virtual team collaboration [37, 40].

The dispersion of team members in a VT make the team and its task less salient to team members [22, 23]. 
A virtual team leader can counter this by communicating frequently with their team members and acting as the boundary spanner among them. The dispersion of team members in VT also prevents impromptu meetings between team members. Virtual team leaders can overcome this challenge by fleshing out and clarifying the details that are typically covered on an ad hoc basis via impromptu meetings in traditional teams.

The geographical distribution causes a low level of initial cohesion and trust among virtual members [18]. Moreover, as team members from different backgrounds will not share common norms and procedure, leaders need to make deliberate efforts to build trust, cohesion, and a shared understanding of norms and procedure to achieve efficient communication and knowledge sharing. A virtual team leader can create a task that is deliverable in the early team life cycle and work with team members to ensure they deliver this task on time. This builds awareness among the team members that other team members can be trusted to complete their assigned work [16].

Based on the above discussion, we believe an effective virtual leadership will improve the effects of self-presence, virtual member trust, and virtual interaction on influencing knowledge sharing in VLE. Thus, the related hypotheses are presented.

Hypothesis 4: The positive relationship between self-presence and knowledge sharing is moderated by virtual leadership, such that this positive relationship is stronger when virtual leadership is high rather than low.
Hypothesis 5: The positive relationship between virtual member trust and knowledge sharing is moderated by virtual leadership, such that this positive relationship is stronger when virtual leadership is high rather than low.

\subsection{Knowledge Sharing and Team Performance}

Nonaka and Takeuchi [29] referred to explicit knowledge as the knowledge that can be easily articulated, codified, stored, and transmitted to others. In the education and teaching system, Young and Muller [45] indicated that daily assignments, lecture notes, and handouts in seminars are examples of explicit knowledge. General virtual communication tools allow for students' interactions to be stored on a website. Kaldoudi et al. [21] described that through the use of Web 2.0 technologies, explicit knowledge can be preserved and added into tacit knowledge. In Kershner et al.'s [24] study, explicit knowledge was found to contribute to learning performance. Agarwal et al. [1] illustrated that web-based technologies facilitate explicit knowledge and onward tacit knowledge sharing, which leads to better results in education. Based on the above research results, we assume that explicit knowledge sharing can facilitate tacit knowledge sharing as well as relate to team performance in VLE.

Hypothesis 6: Explicit knowledge sharing is positively associated with tacit knowledge sharing in VLE.

Hypothesis 7: Explicit knowledge sharing is positively associated with team performance in VLE.

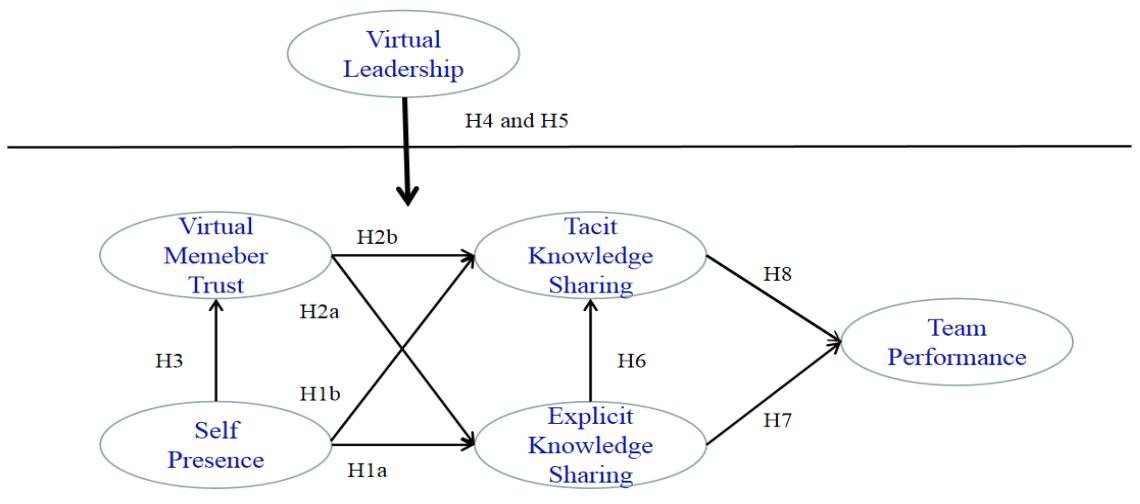

Figure 1: Research model

Polanyi [30] first introduced tacit knowledge in the phrase "we know more than we can tell." Tacit knowledge is knowledge derived from experience, which mainly exists in individuals' minds. Tacit knowledge has been characterized as uncodified, highly personal, and experiential knowledge, and as a result it is difficult to be expressed in words and nearly impossible to capture in databases [34, 37, 39]. Due to the varied nature of tacit knowledge, its sharing takes place through extensive personal contact, regular and close interactions, and shared understanding between parties. Tacit knowledge sharing plays an important role 
in teaching and learning processes. Elton [13] stated that academic writing is based on tacit knowledge rather than explicit knowledge. In a survey-based study, Khumbula and Kyobe [25] concluded that those who share tacit knowledge perform better in group assignments. Hence, we assume that tacit knowledge sharing relates to team performance in VLE.

Hypothesis 8: Tacit knowledge sharing is positively associated with team performance in VLE.

Based on above Hypothesis design, the research model is represented in the following Figure 1.

\section{Methodology}

\subsection{Sample and Procedures}

The participants were full-time undergraduate students who were studying in a randomly selected University in Southwest China. During the Coronavirus pandemic, these undergraduate students engaged in their courses via web-based virtual meetings throughout the whole semester. In total, 106 undergraduate students were invited to participate in this investigation, and ten team leaders were selected among them; these were randomly assigned to ten teams according to their prior semester scholar scores. Finally, with the assistance of the class adviser, 10 team leaders and 88 students were able to complete the data collection successfully via online survey questionnaires.

Questionnaires were sent by personalized online links where a "virtual leadership questionnaire" was sent to the team leaders and other students were asked to complete questionnaires related to "self-presence", "virtual member trust", "knowledge sharing", and "team performance". As a reward, every questionnaire link had a $5 ¥$ e-red packet attached. All surveys were conducted in Chinese, and the English items were translated into Chinese following Brislin's [9] translation-back translation procedure. To ensure that students could understand the survey well, four students were invited to complete the questionnaire prior to the investigation, and a slight modification for our questionnaire was done according to the suggestions of these four students. Data was collected within three days, and the demographic statistics were summarized as follows in Table 1.

Table 1. Demographic results

\begin{tabular}{ccccccccc}
\hline Gender & Frequency & Percent & Age & Frequency & Percent & $\begin{array}{c}\text { Use } \\
\text { experience }\end{array}$ & Frequency & Percent \\
\hline 1 & 56 & $63.6 \%$ & 20 & 13 & $14.8 \%$ & 1 & 36 & $40.9 \%$ \\
2 & 32 & $36.4 \%$ & 21 & 37 & $42 \%$ & 2 & 52 & $59.1 \%$ \\
& & & 22 & 32 & $36.4 \%$ & & & \\
Total & 88 & 100 & & 6 & $6.8 \%$ & & & \\
\hline
\end{tabular}

\subsection{Measures}

3.2.1. Self-presence. Self-presence was measured by three items developed by Behm-Morawitz [4] using a 7point Likert scale $(1=$ mostly disagreeable, $7=$ mostly agreeable). The research items were slightly modified to fit our research context. An illustrative item for selfpresence was "I feel that learning in virtual meeting is an extension of classroom learning". Self-reports were used in this study, because they may provide more accurate data on user self-perceptions than other-reports. The Cronbach's alpha for this factor is 0.872 . Through exploratory factor analysis (EFA), self-presence was found to be in the fifth factor with an eigenvalue of 2.857. To confirm the convergent and discriminant validity of self-presence, we calculated confirmatory factor analysis (CFA). The values of construct reliability (CR) and Average Variance Extracted (AVE) were respectively found to be 0.878 and 0.707 , which ensure the convergent and discriminant validity, respectively, of self-presence.
3.2.2. Virtual Member Trust. Virtual member trust was measured by five items developed by Cook and Wall [11]. Factor items were also modified slightly to fit our research context. An illustrative item for user trust was "I have full confidence in the skills of our virtual team members" Participants were asked to indicate their agreement on a 7-point Likert scale ranging from 1 (mostly disagreeable) to 7 (mostly agreeable). The Cronbach's alpha for this factor was 0.940 . Through EFA, virtual member trust was found to be in the second factor with an eigenvalue of 3.985. To confirm the convergent and discriminant validity of virtual member trust, we calculated the values of CR and AVE in CFA, which were respectively found to be 0.941 and 0.763 , which ensure the convergent and discriminant validity, respectively, of virtual member trust.

3.2.3. Virtual Leadership. Eight leadership roles formed by the Competing Value Framework were adapted in our study. The items used to measure virtual leadership were modified from Denison, Hooijberg, and Quinn [12]. The ten team leaders were asked to indicate 
their agreements via a 7-point Likert scale $(1=$ mostly disagreeable, $7=$ mostly agreeable). The dimensions of the eight virtual leadership roles were "The Innovator Role, The Broker Role, The Produce Role, The Director Role, The Coordinator Role, The Monitor Role, The Facilitator Role, The Mentor Role"; in total, 16 items were measured for this variable.

3.2.4. Knowledge Sharing. Knowledge sharing includes explicit knowledge sharing and tacit knowledge sharing, which were respectively measured through four and six items developed by and slightly modified from Zaqout and Abbas [48]. Illustrative items for explicit knowledge sharing and tacit knowledge sharing were "I share the reports, papers and notes collected from other lecturers for our virtual team members frequently." and "I share my knowledge based on my experience with our virtual team members." A 7point Likert scale $(1=$ mostly disagreeable, $7=$ mostly agreeable) was anchored on knowledge sharing measure items. The Cronbach's alpha of explicit knowledge sharing was 0.942 and the Cronbach's alpha of tacit knowledge sharing was 0.951. Through EFA, explicit knowledge sharing and tacit knowledge sharing were located in the third and fourth factors, respectively, with eigenvalues of 3.281 and 3.138, respectively. The values of CR and AVE in CFA were 0.942/0.936 and $0.802 / 0.787$, respectively, which ensure the convergent and discriminant validity, respectively, of these factors.

3.2.5. Team Performance. Team performance was measured using five items developed by Hinds and
Mortensen [17]; we slightly modified them to fit our research context and anchored them to a 7-point Likert scale $(1=$ mostly disagreeable, $7=$ mostly agreeable $)$. An illustrative item for knowledge sharing was "Our virtual team met its goal as expected." The Cronbach's alpha of explicit knowledge sharing was 0.955 . Through EFA, team performance was found to be in the first factor with an eigenvalue of 4.595. We calculated the values of CR and AVE in CFA and found the respective values to be 0.967 and 0.854 , which ensure the convergent and discriminant validity, respectively, of team performance.

\section{Results}

Before testing the research hypotheses, we calculated the correlations of the research factors. Results revealed that the research factors' square roots of AVE are higher than their inter-correlations which indicates well discriminant validity. Related results are summarized in Table 2.

We use structural equation model (SEM) to test our reseach hypotheses which are calculated in Mplus 8.4 [51]. The values of GOF (goodness of fit) for SEM are $\chi^{2}=337.904, \mathrm{df}=181, \mathrm{CFI}=.925, \mathrm{TLI}=.913$, which present a reasonably good fit. Related research results are presented in Table 3. Considering the multilevel construct of our data, we adopted Hierarchical Linear Modeling (HLM) [50] to test the moderating effects of virtual leadership with the second cross-level interaction.

Table 2. Correlation Coefficients

\begin{tabular}{cccccc}
\hline & SP & VT & EKS & TKS & TP \\
\hline SP & $\mathbf{0 . 8 4 1}$ & & & & \\
VT & $.550^{* *}$ & $\mathbf{0 . 8 7 3}$ & & & \\
EKS & $.586^{* *}$ & $.719^{* *}$ & $\mathbf{0 . 8 9 6}$ & & \\
TKS & $.544^{* *}$ & $.796^{* *}$ & $.793^{* *}$ & $\mathbf{0 . 8 8 7}$ & $.789^{* *}$ \\
TP & $.474^{* *}$ & $.721^{* *}$ & $.726^{* *}$ & $\mathbf{0 . 9 2 4}$ \\
\hline
\end{tabular}

** Correlation is significant at the 0.01 level (2-tailed); SP:self-presence, VT:virtual trust, EKS:explicit knowledge sharing, TKS:tacit knowledge sharing, TP: team performance

Table 3. Hypotheses Testing Results

\begin{tabular}{cccccc}
\hline & Path & Estimate & S.E. & Est./S.E. & P-Value \\
\hline Hypothesis1a & SP-EKS & 0.271 & 0.096 & 2.815 & 0.005 \\
Hypothesis1b & SP-TKS & 0.006 & 0.084 & 0.068 & 0.946 \\
Hypothesis2a & VT-EKS & 0.608 & 0.085 & 7.187 & 0 \\
Hypothesis2b & VT-TKS & 0.475 & 0.097 & 4.873 & 0 \\
Hypothesis3 & SP-VT & 0.58 & 0.081 & 7.189 & 0 \\
Hypothesis6 & EKS-TKS & 0.473 & 0.103 & 4.59 & 0 \\
Hypothesis7 & EKS-TP & 0.337 & 0.135 & 2.502 & 0.012 \\
Hypothesis8 & TKS-TP & 0.543 & 0.132 & 4.116 & 0 \\
\hline SP:self-presence; VT:virtual trust; EKS:explicit knowledge sharing; TKS:tacit knowledge sharing; TP: team performance
\end{tabular}


Table 4. The cross-level moderating effects of virtual leadership

\begin{tabular}{|c|c|c|c|}
\hline & Virtual Trust & $\begin{array}{c}\text { Explicit Knowledge } \\
\text { Sharing }\end{array}$ & $\begin{array}{c}\text { Tacit Knowledge } \\
\text { Sharing }\end{array}$ \\
\hline \multicolumn{4}{|l|}{ Level 1 independent variables } \\
\hline Self-presence & $0.58 * * *$ & $0.271 * * *$ & 0.006 \\
\hline Virtual Trust & & $0.608 * * *$ & $0.475 * * *$ \\
\hline \multicolumn{4}{|l|}{ Cross-level interaction } \\
\hline $\begin{array}{l}\text { Virtual Leadership } \\
\text { presence }\end{array}$ & $0.17 * * *$ & $0.15^{* * *}$ & $0.11 * * *$ \\
\hline Pseudo- $\mathbf{R}^{2}$ & 0.364 & 0.345 & 0.312 \\
\hline
\end{tabular}

Even the results of null models for endogenous variables indicated that no significant between-group variances in virtual trust $\left(\chi^{2}=12.047, \mathrm{df}=9, \mathrm{p}=0.210\right.$, $\mathrm{ICC}_{(1)}=0.033$ ) and knowledge sharing (explicit vs tacit: $\chi^{2}=9.708 / 9.190, \mathrm{df}=9 / 9, \mathrm{p}=0.374 / 0.420, \mathrm{ICC}_{(1)}=$ 0.05/0.04), however, Bryk and Raudenbush [50] suggested that the estimation of accuracy depends on the size of research sample. Because the small research sample $(\mathrm{n}=88)$, not so well ICC values for endogenous variables in our analysis procedure can be understandable. HLM as an appropriate analytic tool to test the group nested data, we proceeded to test the hypotheses 4 and 5 via HLM. The results of second cross-level of moderating effects of virtual leadership are summarized in Table 4.

\section{Discussion}

As virtual communication technologies become increasingly relevant to organizational applications, the reasons for or the achievements of student learning in VLE have attracted substantial attention among researchers and practitioners. Our study explored factors facilitating knowledge sharing (explicit vs tacit) in VLE by deriving self-presence, user trust, and virtual leadership (virtual leadership emphasized on group level). Under the conditions of this study, we discovered a positive association between self-presence and team member trust, which, in turn, had a positive relationship with knowledge sharing. As we conjectured, the positive moderating effects of virtual leadership from a group level further improve the positive relationships between self-presence/virtual member trust and knowledge sharing, which indicate the importance of leadership in VLE.

The results also show that knowledge sharing relates to team performance in VLE, a finding which is consistent with those of existent studies [34, 48]. In our study, explicit knowledge sharing was found to be positively associated with team performance not only directly but also via tacit knowledge sharing. On the one hand, these results corroborate that explicit knowledge sharing contributes to team learning performance in VLE, which supports our H6. On the other hand, the mediating effect of tacit knowledge sharing recalls the results of Elton [13], Shah and Mahmood [34], and Zaqout and Abbas [48], which illustrated that tacit knowledge and explicit knowledge are both better for academic research. Regarding our research results, meaningful implications in both theoretical and practical terms are discussed next.

Our study reinforces the idea that virtual leadership constructs a collaborative learning environment, in which both the relationships of self-presence and virtual member trust influencing knowledge sharing are strengthening. These findings support our research proposition that forming effective leadership is vital for team performance [3]. Self-presence is only positively associated with explicit knowledge sharing directly in VLE which indicates an active interaction between learners and virtual communication technology exists. These results are echos of Behm-Morawits [4] and Yoon et al.'s [44] study in which the vital role of self-presence in VWs are contended. Furthermore, explicit knowledge sharing elicits tacit knowledge sharing in VLE and they are both improving team performance give us a meaning suggestion that increase the interactions between learners and virtual communication technology is a successful way to achieve great learning performance. Because general virtual communication tools take the ability to store students' interactions [27, 49], through it, both learning contents (explicit knowledge) and learning experience (tacit knowledge) can be effective used if efficient communication between users and technology exists.

\section{Limitations and Future Research Directions}

Although these research inferences are thoughtprovoking, our study has a few limitations that should be considered. First, our study was designed using a oneshot case by randomly selecting a University in Southwest China. This method has the advantages of being simple and easy to implement, so it has commonly been used in other studies. However, the reduced experimental control and the use of a pretest as a benchmark may cause the causal results obtained in this study to be less convincing. Future studies should consider generality and the use of larger samples for the 
replication of our research. Secondly, in prior studies related to VWs, self-presence was designed by elements of involvement, sensory fidelity, adaptation/immersion, and interface quality, as well as by levels of proto selfpresence, core self-presence, and extended self-presence [32]. The measures of self-presence used in our study may not accurately represent the construct in its entirety. In future research, a more comprehensive picture of selfpresence should be developed through the inclusion of psychological and behavior measures. Finally, we adopted Quinn's [31] CVF to represent a comprehensive virtual leadership, which includes eight dimensions ranging from the innovator role to the mentor role. This echoes the studies by Faraj et al. [14] and Zakria et al. [47], which recommended that future studies should investigate the importance of virtual team leadership, even though the emergence of leaders in virtual environments is ambiguous and leaders in virtual team situations can either be general team members or specially designated [47]. Questions related to how to achieve effective leadership in VLE and whether certain special leadership roles (e.g., broke role, facilitator role, coordinate role, etc.) are more helpful than others according to different organization backgrounds still demand further research. As noted earlier, as the importance of virtual leadership has drawn increasing attention in virtual environments, more studies should be conducted on virtual leadership from different cultures and from different levels.

\section{References}

[1] P. D. Agarwal, R. Kiran, and A. K. Verma, "Knowledge sharing for stimulating learning environment in institutions of higher technical education", African Journal of Business Management, 6.16, 2012, 5533-5542.

[2] J. Aritz, R. Walker, and P. W. Cardon, "Media use in virtual teams of varying levels of coordination", Business and Professional Communication Quarterly, 81.2, 2018, 222-243.

[3] B. M. Bass, B. J. Avolio, D. I. Jung, and Y. Berson, "Predicting unit performance by assessing transformational and transactional leadership", Journal of Applied Psychology, 88.2, 2003, 207.

[4] E. Behm-Morawitz, "Mirrored selves: The influence of self-presence in a virtual world on health, appearance, and well-being", Computers in Human Behavior, 29.1, 2013, 119-128.

[5] B. S. Bell, and S. W. J. Kozlowski, "A typology of virtual teams: Implications for effective leadership", Group \& Organization Management, 27.1, 2002, 14-49.

[6] A. Benlian, and T, Hess. "The signaling role of IT features in influencing trust and participation in online communities", International Journal of Electronic Commerce, 15.4, 2011, 7-56.

[7] F. Biocca, "The cyborg's dilemma: Progressive embodiment in virtual environments", Journal of computer-mediated communication, 3.2, 1997, JCMC324.
[8] O. Brafman, and R. A. Beckstrom, The starfish and the spider: The unstoppable power of leaderless organizations, Penguin, 2006.

[9] Brislin, Richard W. "Comparative research methodology: Cross-cultural studies", International Journal of Psychology, 11.3 (1976): 215-229.

[10] Y. W. Chuang, "Promoting Consumer Engagement in Online Gaming Communities through Virtual Experience and Social Identity", Sustainability, 12.3, 2020, 855.

[11] J. Cook, and T. Wall, "New work attitude measures of trust, organizational commitment and personal need nonfulfilment", Journal of occupational psychology, 53.1, 1980, 39-52.

[12] D. R. Denison, R. Hooijberg, and R. E. Quinn, "Paradox and performance: Toward a theory of behavioral complexity in managerial leadership", Organization Science, 6.5, 1995, 524-540.

[13] L. Elton, "Academic writing and tacit knowledge", Teaching in Higher Education, 15.2, 2010, 151-160.

[14] S. Faraj, S. Kudaravalli, and M. Wasko, "Leading collaboration in online communities", MIS Quarterly, 39.2, 2015.

[15] S. M. Farmer, and C. W. Hyatt, "Effects of task language demands and task complexity on computer-mediated work groups. Small Group Research, 25.3, 1994, 331-366.

[16] S. J. Han, M. Kim, M. Beyerlein, and D. DeRosa, "Leadership Role Effectiveness as a Mediator of Team Performance in New Product Development Virtual Teams", Journal of Leadership Studies, 13.4, 2020, 20-36.

[17] P. J. Hinds, and M. Mortensen, "Understanding conflict in geographically distributed teams: The moderating effects of shared identity, shared context, and spontaneous communication", Organization Science, 16.3, 2005, 290307.

[18] S. L. Jarvenpaa, and T. R. Shaw, "Global virtual teams: Integrating models of trust", Organizational Virtualness, 1998, 35-52.

[19] S. D. Johnson, C. Suriya, S. W. Yoon, J. V. Berrett, and J. L. Fleur, "Team development and group processes of virtual learning teams", Computers \& Education, 39.4, 2002, 379-393.

[20] A. Joshi, M. B. Lazarova, and H. Liao, "Getting everyone on board: The role of inspirational leadership in geographically dispersed teams", Organization Science, 20.1, 2009, 240-252.

[21] E. Kaldoudi, S. Konstantinidis, and P. D. Bamidis, "Web advances in education: interactive, collaborative learning via Web 2.0.", Affective, interactive and cognitive methods for E-learning design: creating an optimal education experience, IGI Global, 2010, 32-50.

[22] Kayworth, Timothy R., and Dorothy E. Leidner. "Leadership effectiveness in global virtual teams." Journal of management information systems 18.3 (2002): 7-40.

[23] T. Kayworth, and D. Leidner, "The global virtual manager: A prescription for success", European Management Journal, 18.2, 2000, 183-194.

[24] R. Kershner, D. Pedder, and C. Doddington, "Professional learning during a schools-university partnership Master of Education course: teachers' perspectives of their learning experiences", Teachers and Teaching, 19.1, 2013, 33-49. 
[25] C. Khumbula, and M. Kyobe, "Investigating the extent to which students share tacit knowledge using mobile phones in group projects", Proceedings of the South African Institute of Computer Scientists and Information Technologists Conference on Knowledge, Innovation and Leadership in a Diverse, Multidisciplinary Environment, 2011.

[26] T. Kohler, J. Fueller, K. Matzler, D. Stieger, and J. Füller, "Co-creation in virtual worlds: The design of the user experience", MIS Quarterly, 2011, 773-788.

[27] M. G. Moore, G. Kearsley, Distance education: A systems view of online learning, Cengage Learning, 2011.

[28] S. Nevo, D. Nevo, and E. Carmel. "Unlocking the business potential of virtual worlds", MIT Sloan Management Review, 52.3, 2011, 14.

[29] I, Nonaka, and H. Takeuchi. The knowledge-creating company: How Japanese companies create the dynamics of innovation, Oxford university press, 1995.

[30] M. Polanyi, "The logic of tacit inference", Philosophy, 41.155, 1966, 1-18.

[31] R. E. Quinn, Beyond rational management: Mastering the paradoxes and competing demands of high performance, Jossey-Bass, 1988.

[32] R. Ratan, and B. S. Hasler, "Exploring self-presence in collaborative virtual teams", PsychNology Journal, 8.1, 2010.

[33] F. C. Serçe, K. Swigger, F. N. Alpaslan, R. Brazile, G. Dafoulas, and V. Lopez, "Online collaboration: Collaborative behavior patterns and factors affecting globally distributed team performance", Computers in Human Behavior, 27. 1, 2011, 490-503.

[34] S. R. Shah, and K. Mahmood, "Contributing factors in knowledge sharing for performance of university students in teachers' training programs", Library Management, 2016.

[35] S. C. Srivastava, and S. Chandra, "Social presence in virtual world collaboration: An uncertainty reduction perspective using a mixed methods approach", MIS Quarterly, 42.3, 2018, 779-804.

[36] K. D. Strang, "Examining effective technology project leadership traits and behaviors", Computers in Human Behavior, 23.1, 2007, 424-462.

[37] G. Susman, and A. Majchrzak, "Research issues in knowledge management and virtual collaboration in new product development: An introductory essay", Journal of Engineering and Technology Management, 20(1-2), 2003, $1-5$.

[38] R. Tamborini, and S. Paul, "The role of presence in the experience of electronic games", Playing video games: Motives, responses, and consequences, 2006, 225-240.
[39] R. Topchyan, "Does social presence relate to knowledge sharing in virtual learning teams?", Knowledge Management \& E-Learning: An International Journal, 8.4, 2016, 646-660.

[40] W. L. Tullar, and P. R. Kaiser. "The effect of process training on process and outcomes in virtual groups", The Journal of Business Communication (1973), 37.4, 2000, 408-426.

[41] M. Wasko, R. Teigland, D. Leidner, and S. Jarvenpaa, "Stepping into the internet: New ventures in virtual worlds", MIS Quarterly, 35.3, 2011,645-652.

[42] R. Yilmaz, F. G. K. Yilmaz, and H. Keser, "Vertical versus shared e-leadership approach in online projectbased learning: a comparison of self-regulated learning skills, motivation and group collaboration processes", Journal of Computing in Higher Education, 2020, 1-27.

[43] Y. Yoo, and M. Alavi, "Emergent leadership in virtual teams: what do emergent leaders do?", Information and Organization, 14.1, 2004, 27-58.

[44] S. Y. Yoon, Y. J. Choi, and H. Oh, "User attributes in processing 3D VR-enabled showroom: Gender, visual cognitive styles, and the sense of presence", International Journal of Human-Computer Studies, 82, 2015, 1-10.

[45] M. Young, and J. Muller, "Three educational scenarios for the future: Lessons from the sociology of knowledge", European journal of education, 45.1, 2010, 11-27.

[46] G. Yukl, "How leaders influence organizational effectiveness", The Leadership Quarterly, 19.6, 2008, 708-722.

[47] N. Zakaria, A. Amelinckx, and D. Wilemon, "Working together apart? Building a knowledge-sharing culture for global virtual teams", Creativity and Innovation Management, 13.1, 2004, 15-29.

[48] F. Zaqout, and M. Abbas, "Towards a model for understanding the influence of the factors that stimulate university students' engagement and performance in knowledge sharing”, Library Review, 2012.

[49] I. Ko, and Y. Ko, "A Study on the factors facilitating the effectiveness of Web-based collaborative learning: Focused on situation, interaction, system", Journal of Information Technology Applications \& Management, 13.4, 2006, 197-214.

[50] A. S. Bryk, and S. W. Raudenbush, Hierarchical linear models: Applications and data analysis methods, Sage Publications, Inc, 1992.

[51] L. K. Muthén, and B. Muthen. Mplus user's guide: Statistical analysis with latent variables, user's guide, Muthén \& Muthén, 2017. 